\title{
Correspondence
}

\section{Workshops on court procedures}

\section{DEAR SIRS}

I was interested to read Dr Healey's letter describing his experience of the High Court (Psychiatric Bulletin, October 1989, 13, 570-571). As he found, the rules of legal procedure, such as that answers to barristers' questions should be addressed to the judge, are not obvious. At a recent residential meeting of the Child \& Adolescent Psychiatry Section of the College, I attended a workshop run by a judge which included role play of an expert witness undergoing cross-examination. The legal conventions and court procedures rapidly became clear as did some of the assumptions which lawyers or judges are likely to make in considering cases involving children.

I would like to suggest that workshops of this sort could be a very useful training experience for child or adult psychiatrists. There is scope both for experiential learning about court procedures and for acquiring an understanding of how lawyers and judges think about psychiatric or child care issues. Psychiatrists at the workshop expressed discomfort with the adversarial legal system but it was interesting to hear the judge's alternative view that the maximum "truth" about a case might be reached through it. Although child psychiatrists may be seeking changes in legislation and court procedures, we also have to work within the system as it is and I agree with $\mathrm{Dr}$ Healey that we should be careful to learn its rules.

Royal Manchester Children's Hospital

ANNE GILCHRIST

Jesson House, Swinton, Manchester M27 IFG

\section{Mental health review tribunals}

\section{DEAR SIRS}

Unless I have misread Dr Petrie's question (Psychiatric Bulletin, October 1989, 13, 571), I would venture to suggest that the answer may be found in Section 131 of the Mental Health Act (Subsection 1) where it states that nothing in the Act shall be construed as preventing a patient "from remaining in any hospital or mental nursing home in pursuance of such arrangements after he has ceased to be so liable to be detained". It is, of course, unlikely that such a practice would apply to a patient who had been detained in a special hospital but I would submit, at least in theory, that such an informal admission could occur in the case of a patient who had been detained under a restriction order in an ordinary psychiatric facility and then discharged. It would be interesting to have other views upon a matter that has interesting implications.

Herschel Prins

(Lay member, Mental Health Review Tribunal, Trent Region)

I Home Close Road

Houghton-on-the-Hill

Leicester LE7 9GT

\section{Forensic questions in the multiple choice paper}

DeAR SIRS

I have read the letter from Twelve Angry 'Men' in the Psychiatric Bulletin of September 1989 with interest. I would suggest that the Examination SubCommittee should think very carefully before changing the thrust of the forensic questions in the multiple choice paper, as the authors of this letter suggest. I agree with Professor Morgan that matters relevant to forensic and legal psychiatry are indeed of immense importance and this is no less relevant to Irish and Scottish candidates, many of whom apply for jobs in England and Wales after they have passed the Membership. If it were the general rule that Irish and Scottish candidates stayed in their own countries for the rest of their training and as consultants, then there would perhaps be a case for including more questions relating to their own jurisdictions, but this is not so at the present time. However, some knowledge of the Scottish system is relevant to Irish and English trainees who move to Scotland and there may well be more case for including questions relating to the Scottish system in the examination. It is true, however, that there are many general questions which do not relate to matters of law that can be asked and perhaps a few more of these could be considered in future.

I am not a member of the Examination SubCommittee.

University Department of Psychiatry

Reaside Clinic, Rubery, Rednal

Birmingham B45 9BE

\section{Suicidal patients - the effect on staff}

DEAR SIRS

Dr Rossiter (Psychiatric Bulletin, September 1989, 13, 495-496) found several of her nurses to have a pessimistic attitude towards their patients when 